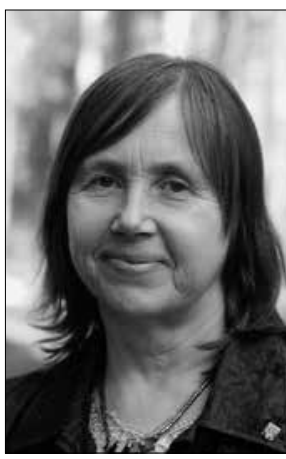

https://doi.org/10.24101/logos.2017.58

\title{
JÜRATĖ LANDSBERGYTĖ-BECHER
}

Lietuvos kultūros tyrimo institutas

Lithuanian Culture Research Institute

\section{EGZISTENCIALIZMO MOTYVAI ONUTĖS NARBUTAITĖS KÜRYBOJE. OPERA „KORNETAS"

\author{
Egzistencializm Motifs in Onute Narbutaite \\ Creative Work. Opera "Cornet"
}

\begin{abstract}
SUMMARY
The work of Lithuanian composer Onute Narbutaite is very important for a Lithuanian a presence in the contemporary discourse of world culture. Her music is based on multicultural contexts, personality matters and personal life experience, connected with the history of the Lithuanian capital of Vilnius. Another source for her creativity is the early modernism of European culture in I half of XX century. There she expressed the signs of existencial philosophy inspired by Reiner Maria Rilke's poetry, life and environment contextes. Narbutaite's creative work leads into the world of Rilke images: Vigilias, transcendental landscapes and day-dreams visions. The composer transforms Rilke's contexts in her own way to connect with the dream world and great culture of modern Europe. That expresses the concept of her newest work multitude in multicultural means the opera "Cornet" (2014) after R.M.Rilke ("Die Weise von Liebe und Tod des Cornets Christoph Rilke", 1906). Nevertheless that presents another research mystery for her interpreters. Narbutaite and Rilke are there on their mission to reconstruct past times.
\end{abstract}

\section{SANTRAUKA}

Onutės Narbutaitės kūryba yra vienas ryškiausių Lietuvos kultūros dabarties ženklų pasaulyje. Jos išskirtinumą lemia keli ypatingi veiksniai: multikultūrinis europinis kontekstualumas ir asmeninis meno ir gyvenimo jungties patyrimas, būdingas romantikų kūrybinei prigimčiai. Čia Narbutaitė save labai stipriai susieja su Vilniumi, jo kultūros istorija ir XX a. pradžios europiniais kontekstais. Kompozitorès kūryboje atsiranda ir vis labiau ryškejja egzistencializmo bruožai, kuriuos lemia jai itin artimi R. M. Rilke's tekstai ir gyvenimo puslapiai. Tai atveda Narbutaitę i nakties vigilijų, transcendentinių šifrų ir dienos sapnų pasaulį, 
kuris atsiveria jos naujausiame kūrinyje - daugiasluoksnèje operoje "Kornetas" (2014) pagal R. M. Rilkę. Šis kūrinys tampa savotiška lietuvių muzikologijos įžvalgų, nuojautų ir tyrinejjimų misterija, refleksijų centru, atliekančiu atskirą egzistencinio meno interpretacijos misiją.

\section{EGZISTENCIALIZMAS LIETUVOS MODERNYBĖJE}

Egzistencializmo filosofijos pèdsakai moderniojoje Lietuvos kultūroje nèra išsiskleidę. Galbūt tai lèmė laiko diktuojamo užribio drama. Sovietų okupacijos sąlygomis prisitaikanti ir proveržiu ieškanti kūrybinè mintis, meninè pasaulio refleksija buvo paveikta vadinamojo iškreipto tikrovès vaizdo - nepripažintos tiesos, užkardytą Vakaru erdvę eliminuojančios sisteminès diskursų blokados. Prasiveržimu „iš netekties gelmių" metodai formavosi kūrybos metaforoje, kiek kitaip beieškant užribių ir praeities fragmentu, skiautinių, prasminių sentimentu, atsiveriančių padvelkus egzistencializmo vidinès laisvès vèjui.
Vis dèlto esminès egzistencinès filosofijos sampratos, nuaidejusios dar Vytauto Mačernio (1921-1945) poezijoje, tapo itin stipriais Vakaru pasaulio traukos centrais. Sovietmečiu tai ženklino ir Jeanas Paulis Sartre'as, kuris su žmona Simone de Bovuar lankèsi Lietuvoje ir išliko i̇simenančiose, tarsi sustojusio Europos laiko Antano Sutkaus fotografijose Neringos kopu peizaže. O ypač vidine skausmo drama mąstančiuosius įelektrino Alberto Camus knygu (išleistų 7-8 dešimtmečiais) tekstai, jie lèmé vidinio išsilaisvinimo kodus prasminiam filosofijos „vartu atidarymui“ Lietuvoje.

\section{EGZISTENCIALIZMAS KAIP BÜTIES SKAUSMAS MUZIKOJE: NARBUTAITE்}

Vakaru pasaulio krizès paskatinti egzistencializmo motyvai, pradejję savo kelią jaunojo V. Mačernio eilèraščiuose, žuvo kartu su juo karo pabaigoje ir pokario pradžioje... Jos tikroveje formavosi kita istoriniu koliziju subrandinta Lietuvos sąmonè. Vèliau išsiliejusi šiaurietiškos dimensijos sukauptomis formomis, baltiškuoju minimalizmu su savo antiideologine gynybine linija egzistenciniam atsilaikymui ir begalybès traukai. Alternatyvoje - Sigito Gedos (1943-2008) Lietuvos globalios transformacijos vyksmas, lietuviams gimstantis ir Kaukaze, pasipriešinimu židinyje, neleidžiantis užsi- daryti "vienui vienu“ rezistencinèje „tamsos širdyje“. Šių tendencijų sankirtai XX-XXI amžių sandūroje lietuviškajam Naujajam romantizmui peraugus ị ribinès situacijos dramaturgiją muzikoje reikšmingai atstovauja Onute Narbutaite (g. 1956), kuri vèl savaip sugrižta prie egzistencializmo kontekstú. Čia pasitvirtina esminè egzistencializmo nuostata: laisvo kūrybos akto priešpriešinimas kaustančiai sistemai - tikrovès prievartinei tvarkai. Vis dellto O. Narbutaite tebetęsia Camus "svetimo“ supančiam pasauliui individualizmo tradicija, savotiškai vieniša, beieškanti europinių, o ne 
lietuviškos archaikos motyvų ir simboliu, istorijos ir meno ryšio kontekstu, ženklu ir sferu prisodrintoje muzikos kalboje. Narbutaitė tarsi laviruoja savo „kelyje i tylą" tarp kultūros klodų ir skausmingų praeities pajautu, asmeniniu šeimos istorijos patirčių. Čia glūdi daugiasluoksnès jos kūrybos atsakymai i klausimus, kodèl Narbutaitei artimas egzistencinès vienišojo būties pojūtis, kas tai lèmè ir lemia, kodèl i ji sugrižtama po transformaciju jau visai kitu laiku, kitoje erdvëje.

Galima teigti, kad egzistuoja ir gilus dvieju ar triju tikroviu antagonizmas: svetimo dabarties pasaulio, iz atminti nugrimzdusio praeities pasaulio ir amžino išsilaisvinimo akto - individo siekiu ir ilgesių neišpildžiusio pasaulio susitikimas. Taip tiesiogine prasme migruojama ¿ egzistencializma, Europos moderno pradžią ir psichologinès gelmės vaizdiniją. Narbutaite į XX a. I pusę sugrižta per vieną Lietuvos intelektualinès dvasios centru, savo mylimą vokiečių poetą filosofą Reinerị Maria Rilke'ę (1875-1926). Daug veiksnių lèmè šiu dvieju kūrëju artuma laiko ir erdvès virsme, besikartojančiose amžiu sandūros kolizijose. Rilke's kon- tekstų artumas Rytų Europai, vokiečių kalba ir jos gilus pajautimas, žinojimas, vidiniai intelektualiniai resursai ir patirtis leido pintis kultūroms, vienoms per kitas „siekti išsigelbèjimo“, kilti reikšmėmis per vidinius struktūrinius meno kalbos takus alsuojant to paties Baltijos jūros vèjo nostalgijos dvelksmui, klausantis vidinio vienišumo balsų. Pasaulejjauta būnant svetimam, vienišam, klajūnui ir svečiui pasaulio namuose - toks kultūrinio mentaliteto „raštas" su kontekstais būdingas ir Narbutaitei, intravertei autsaiderei lietuviškuose savasties ieškojimuose, ir jos dvasios broliui Rilke'i. Kompozitorè, kuri yra ir talentinga poeté, literaté, tapytoja bei intelektuali kultūrologè, čia ieško žodžio byrèjimo paslapčių, intonacinių ląstelių transformacijos, dvelksmu, transcendentalios erdvės, kurios atžvilgiu muzika būtų tik "taškas" ar daugtaškis, impulsas tolesniems atsiverimams. Formuojasi egzistencialistiškai nuspalvinta begalinio atsisveikinimo melodija-vizija, kupina ekstramuzikinès semantikos, gebejjimo perteikti psichikos vingius, psichikos intonaciją ${ }^{1}$ ir naują psichologinès gelmès interpretacija.

\section{TRANSCENDENTINIAI ŠIFRAI (JASPERSAS)}

Egzistencializmas Narbutaitès muzikoje ateina ir iš dievoieškos, pakeičiančios savasties ieškojimą nusigręžiant nuo archaikos ir minimalizmo archetipu „kulto“, pasiliekant tik maldos, choralo, meninio sakralumo ịvaizdžiuose. Čia padeda ir Rilke's apokaliptinio universumo, ir A. Malraux „meno kūrinių muziejaus" koncepcija, tačiau Narbutaitès vidini pasirinkimą, jos nuostatas kaip „kelią ì tylą" savaip, gal intuityviai siekiant aprèpti visumą "iš netekties gelmiü", lètai formuoja Karlo Jasperso (1883-1969) egzistencializmas, religiniai ir transcendencijos šifrai, metaforu kalbos „antroji erdvè" ir muzikos kaip pasauli suvaldančo sakralumo ideja par exellence. Narbutaitei būdingas išskirtinumas tarp kitų Lietuvos meno pasaulio dalyvių sutampa su Jasperso apibrèžtu kūrèjo sta- 
tusu: „Didis menininkas yra lyg šventasis savo polèkyje, siekia transcendencijos, susiliejimo su amžinuoju pradu. ${ }^{2}$ Tai įžvalgiai pažymi šiuolaikinès muzikos kritikas, atlikejjas ir kompozitorius Šarūnas Nakas: „I I Narbutaitès muzikos vakarus einama lyg i mišias“", t. y. su nuostata pakilti dvasia, medituoti, išsigryninti neįsileidžiant jokio "svetimo" poveikio, tarsi šventu artumu, vidiniu intymiu santykiu su kūryba užkardyti bet kokio hibridiškumo ir „pavargusios nuo netikrumo" tikrovès šiurkštaus įsibrovimo tikimybę. Narbutaitès apibūdinimui tinka ir kita Jasperso mintis: „Menininko didybè reiškiasi ne originalumu, o egzistencine neregima jèga <...>. Kaip egzistencija, mes susiję su Dievu - transcendencija; to ryšio terpè - daiktų kalba, kuri juos padaro šifrais arba simboliais. "4
Kompozitorè iš tiesų išsiskleidžia simbolių kontekstuose ir įvairių laikų kūrybos idejjų laukuose ieškodama sau artimų skausmo, menininko likimo ženklų nuotrupu, kuriose susilieja ir jos asmeninè patirtis, intelektas, talentas ištirti ir jungti reiškinius.

Netgi jos egzistencinè kūrybos valia, išaugusi iš įvairių kitų kūrybų ir patirčių kontekstų glūdi būtent šioje šventumo projekcijoje, nuolankume „transcendentinei sąmonei“", kaip tai apibūdina Jaspersas: „Didis menininkas sąmoningai pajungia savo kūrybą transcendentinei sąmonei <...>. Tokiu atveju istorija yra kažkas daugiau: ji yra Dievo atsivėrimo vieta. “5 Tai itin artima Narbutaitei nuostata, dar sutvirtinama jos muzikinès gelmès ir akustinès erdvès muzikoje transcendentalumo pojūčio.

\section{RILKE'S ARTUMAS}

Ryškiausias šiuo požiūriu kompozitorès kūrinys, dabarties ir visą jos kūrybą telkiančios koncepcijos projektas yra opera „Kornetas“ (2014) pagal Rilke's prozos poemą "Die Weise von Liebe und Tod des Cornets Christoph Rilke“ (1906). Šiame scenos besiprašančiame kūrinyje Narbutaitè, pasitelkusi egzistencialistų išaukštinto kūrybinès laisvès akto transformacini vyksma, tiesiogine šio žodžio prasme išskleidžia Jasperso „transcendencijos šifrų“ kalbą. Sceninis vaizdinys yra kupinas ir kitų egzistencializmo motyvų transformacijos: meno kūrinio „,muziejaus" konceptualumo, operos žanro ir Rilke's kritikos pozicijų susidūrimo klausimo, kūrëjo ir ji supančio kritikuojančio pasaulio sankirtu, psichologinès gelmès „dienos sapnų", tikrovès virsmo, muzikos universumo - pasaulio valios nušvitimų trajektorijos. Tačiau nepaisant šios transcendentiniu šifru didybès ir jos projekcijos kintančiuose vaizdiniuose, operoje arba, kaip autore ivvardija, „improvizacijoje pagal Rilke'ę" lemia egzistencialistinè individo jaunystès polèkio ir ji supančio "svetimo karo" tikrovès susidūrimo drama, fatališka meilès, mirties ir meno prasmių kolizija, sustingusi muzikos scenos ženklų lauke. Tai ir figūratyvus motyvas - vieno taško kartojimas vieną garsą skambinančios Pianistès vaizdinio finalinis gestas arba ,transcendentinis šifras", prisilietimas prie laiko ir būties gelmių subtilia nuojautos išraiškos detale. Toks „„šifrų skleidimasis“ būdin- 
gas Narbutaitès muzikos kalbai: detalès byrëjimas, žodžio-garso intonacijos išgryninimas, iškèlimas erdvèje, sferų dvelksmai, trapumo apčiuopa, adekvati Rilke's reikšmių sluoksniavimo ir stebejimo poetikai jo žvilgsnyje i reiškiniu gelmes. Ypač jo atitikime alsuoja pasidavimas tylai, sulètintai laiko tèkmei.

Lietuvių autorè susikoncentruoja $\mathfrak{i}$ kelias pamatines Rilke's egzistencinio braižo reikšmes: detalès šventumo paradigma, laiko stabdyma, vienatvę pasaulyje. Juk Rilke'i ir rožès žiedas turi ne panteistinès gamtos filosofijos, ne paties grožio - gèlés archetipo, o laiko transcendencijos - „miego po šitiek vokų" ir vidinio prieštaravimo, sunkumo, tylos slinkties estetiką. Fenomenas yra pripildytas asmeninès laiko tèkmès pojūčio ir skleidžiasi „„̇stabiom rievèm“ (,Rievèm istabiom gyvenu aš tolydžio per daiktus jos plinta aplink")6. Tai ir Narbutaitei būdingas raiškos fenomenas: apdainuoti reikšmių reikšmes, kontekstus, stebèti ženklus, šauktis sustojusio laiko ir praeities sugrižimo. Transformuoti praeities dimensiją i viršlaikini lygmeni detalę apgaubiant ypatingu dèmesiu, skaudžia trapumo pajauta ir nukreipti i daugiasluoksnę sampratu raidą. Transformuoti ją „rievèm, plintančiom aplink daiktus“.

Būtent tai ir stebime operoje „Kornetas": rilkiškujų reikšmių savotišką naujai sutelktą gyvenimo projekciją - nuo laužo scenos, rožès žiedo, trimito, vẻliavos, atskiro žodžio ir jo skiemens magijos. Žodžiai tampa ženklais: Kornetas, vèliava, naktis, širdis, sapnų mergaite, jūreiviai, laivas, sirena, moteris. Jie dalyvauja tarsi lètame "mirties šokyje“, sukabintoje gestu sekos grandineje leisdami muzikai kurti požeminès grèsmès fono parabolę arba atsiplèšti i abstrakcija, išsilydyti i meditaciją ir galutinai jungiančiais gestais "sudèti taškus“.

Egzistencialistinis Rilke's ir jo aplinkos draugu - dvasios broliu - bei personažu grandies „mirties šokis“ Korneto likimo kataklizme, kuriame ir visi stebintys, supantys, laukiantys, svarstantys tampa dalyviais, yra gilios egzistencinès nuostatos pamatas: būtis svarbesnè už esmę. Ieškoma prasmès beprasmëje karo tikrovejje, prasmè iškyla tik transcendentiniame peizaže, kūrybos palytètoje raišku erdveje. Čia prasiveržia vaizdinio prerogatyva: arkliu jojimo ritmas, rausvu gaisro pašvaisčiu toluma, kariuomenès judèjimas, sargybos laužas ilsintis „,sustojus laikui“ - transcendentuojančiame vizionieriaus lauke.

Taigi Narbutaitė čia siekia „išlaisvinti“ Rilke's pasąmonę - sapnus, nuojautas, vienatvès ilgesio giesmes. Tuo būdu ji tarsi pranoksta egzistencializmo ideju peizažus, transcendentinius šifrus (Jaspers), tapusius operos dramaturgijos kodais, ir transformuoja secesini „meno kūrinio muziejų“ i kitą idèjinę sapno sferą. Prasideda Narbutaitei ir mūsų mentalitetui būdingas esminis sąmonès ir pasąmonès dialogas, pasitelkiant Sigmundo Freudo, Carlo Gustavo Jungo "dienos sapnus", nuojautas, pranašystes, vizijas, pasąmonès sluoksnių išlaisvinimą ir archetipu transformacijas. Taip Rilke čia papildomas naujais meno filosofijos kontekstais, XX a. vidurio diskursu ir Rytų-Vakaru tapatybes sugeriančia gelmès psichologijos dimensija. Šiuo požiūriu opera „Kornetas“amžių kultūros žemèlapyje atlieka keliu žvalgymo vaidmenị, fiksuoja viršlaikinę jau ne-istorinę $b \bar{u} t i$ ir jos esmingumo skaudžiąsias 
ribas (ribines situacijas). Taip nugrimzdus i rilkiškąji diskursą "Kornete“, jo autore išlieka daugiapolèje racionalaus- iracionalaus egzistencializmo dimensijoje su ypatingu savo asmeniniu aukštumu kultūros traukos prisodrintu kontekstu.

\section{SĄMONĖS IR PASAMONĖS SANKIRTA. JUNGO ŠEŠĖLIS}

Komplikuota „Korneto“ dramaturgija siekia aprèpti ši daugiapoli Rilke's, ir ne tik, erdvių kontekstualumą panerdama i̇ psichoanalizės sferas. Muzikos viršlaikiškumo idejja Narbutaitei iškyla i operos "viršutinį“ transcendentalini veiksmą, ì liniją virš konkretaus būties tragizmo, kančios ir karo siaubo išskleistų apokalipsių. Čia susigeria abstrahuojami modernistu psichiniu patologiju vaizdiniai (O. Kokoschkos „Žmogžudys - moteru viltis"), atsveriami klasiku minties ironijos (J. W. Goehte's „Faustas", Raganos virtuvè). Susiklosto komplikuotos racionalizmo-iracionalizmo diversijos, atspindinčios sąmonès struktūrų įcentravimo ir pasąmonès išlaisvinimo diskursa, kurị apgaubia savotiškas „transcendentinių šifrų" kodais išreikštas muzikos ir vaizdo judèjimas kitame laike. Sąmonès ir pasąmonès vaizdiniai operoje rikiuojasi $\mathfrak{i}$ autorés įvardijamu „,improvizaciju“ grandinę trijuose 18 scenu paveiksluose. Pasąmonès - tai „dienos sapnai“, išlaisvintieji iš realybės, kitos tikrovés vaizdiniai, suteikiantys laiko kelionės polèkį. Tai tarsi autorès atradimas, interpretuojant Rilke'ę, atsveriamas alternatyviu muzikos, literatūros, meno istoriko žvilgsniu - dokumentuotomis Rilke's gyvenimo scenomis. Jų susipynimas kartu su kultūriniais laiko neribotais kontekstais sudaro tą ",meno-mokslo secesija“", kurioje svarbu atsirinkti, o dar svarbiau išsivaduoti iš racionalumo ir pajusti emocinius-juslinius tragedijos akcentus (kuo ir yra išskirtinè Rilke's proza).

Opera prasideda İžanga, kur ižengia pasamone: sapnų mergaitè, žaidžiantys berniukai, Būgnininkas. Tai pirmieji "dienos sapnų" pagal Rilke'ę ženklai, bylojantys autorés iniciatyvą perkurti „Sakmę apie Kornetą...", pakreipti ją savo viziju ir atrastų kontekstu, tyrinëjimu vaga. Skamba muzika meditatyviais Rilke's ir kitu poetu eilèraščiu tekstais (dar neliečiant pačios "Sakmès..."): „Rose, oh reiner Widerspruch...", "Herbsttag“, O. Kokoshkos „Träumende Knaben“. Pirmoji scena dar vis skleidžia sapno dramaturginę inspiraciją, aiškina jos strategiją: „Tuomet jau galèsite atiduoti savo teptuką vedžioti fantazijai. Ir rezultatas priklausys nebe nuo žmogaus, o nuo dangaus" (iš tapybos recepto, kuri XI a. pateikè kinu dailininkas Song Di) ${ }^{7}$. Autore taip pat cituoja Rilke's tekstą apie Georgo Traklio "Sebastijoną sapne“ ir, matyt, iš ten semiasi sapno idejos gelminių inspiracijų. Taigi nuo pat pradžių panyrama i platu Rilke's kontekstų pasauli, leidžiama Korneto istorijai kol kas likti paribių lauke, tik vèliau „i sceną pasikviečiant" jos tragedinius akcentus. Kornetas čia beveik tampa vienu iš savo antrininku (o autorès koncepcijoje - ir Rilke's antrininku), i pirmajji planą iškylant Kokoshkos „Sapnuojančių berniu$\mathrm{ku}^{\prime \prime}$ vaizdiniams. 


\section{KORNETAS IR JUNGAS}

Taip išlaisvindama pasąmonę, autorè suteikia sąmonei realius rilkiškuosius atsvaros akcentus. Pirma, tai - Korneto istorijos kontekstai: austrų-turkų XVII a. karo vaizdiniai, gaisru dangus, vèliava (Kornetas - pulko vèliavnešys), šokanti Mirtis (asociacija: „Mirties šokis“ viduramžiu tapyboje, freskose), nukankinta mergaitè, prancūzas Markizas, laužo scena, meilès ilgesys su rožès motyvu. Tai nuo 3 scenos prasidejjęs veiksmas ir operos pabaiga. Antra, tai - Rilke's gyvenimo dokumentika, laiškai, draugu ir kritiku nuomonès dèl „Korneto“ teatralizavimo... pastarosios scenos operoje yra gana nelauktos, moderniai intermedialios, suteikiančios pačiam Rilke'i operos veikejjo ir antrininko šešèlinę dimensija, gal ir per daug perkraunančios libreta, nukreipiančios jị $i$ intelektualų mokslinio tyrinëjimo ir detalizavimo lygmeni. Antra vertus, tai dar labiau paryškina ir poeto egzistencinę dramą. Tai yra antroji pirmo paveikslo scena, svarbus dramaturginis akcentas operos pradžioje prieš prasidedant veiksmui. Dvi sąmonès operoje - racionalaus dramaturgijos paruošimo ir kontekstualizavimo linijos vis dèlto centruojamos $i$ pasąmonę - sapno dramaturgija, transcendentalizmo ir Jungo vizijų sferą. Jungiškasis sluoksnis čia - kulminaciniai du paveikslai (bei inspiracijos iš pirmojo paveikslo vaizdu) su savita gelmès psichologijos transformacijų simbolika: Pirmas sapnas - Tolimas miestas. Balsai. Antras sapnas - Tolima sala. Sodas. Trečias sapnas - Laivas. Miegantys. Ketvirtas sapnas - Šaukiantys jūreiviai. Penktas sapnas - Užmirštas miestas. Pilis. Sodas. Bokštas. Vèliavos sapnas. Bent šešios iš
18 scenu ivardintos kaip sapnai ${ }^{8}$. Narbutaitè čia tarsi transformuoja Rilke'ę i jungo pamatines reikšmes ir vizijas: Bokštas, labirintas ${ }^{9}$, jo ornamentu kylantis scenovaizdis, kurị atitinka ir muzikinè raiška, Savasties nušvitimo kelio dramaturgi$\mathrm{ja}^{10}$ - vagneriškoji meilès dueto „begalinè melodija“. Taip tarsi išlaisvinama tikroji Korneto Savastis - meilès aistra, vidinè galia, energija, šalia kurios Korneto/Rilke's supantis pasaulis atrodo neviltinga karo gaisru niokojama egzistencinè $t u s ̌-$ tuma. Ši dimensija irgi tvyro šalia ir siekia būti ịvardinta. Tikroji - ir muzikos - galia slypi meilès dueto kylančiame melodiniame "labirinte“ ir Bokšto simbolyje. Čia kompozitorè jau nèra Jasperso "transcendentiniu peizažųu paveikta, o pasiduoda galingai vèlyvojo romantizmo Richardo Wagnerio dramma per musica srovei („Tristano ir Izoldos“ finalas), susiliejančiai su egzistencializmo iškelta asmenybès laisvès ir pasaulio absurdiškumo sandūra. Rilke's transformacija i Junga, i išlaisvintus archetipinius vaizdinius tampa laikinè ir natūrali XX-XXI a. mąstymo perspektyvoje.

Narbutaitė muzikoje realizuoja „tvyrančią erdvèje Rilke's meninių idèjų sferą". Tai Laikas („Herr, ist die Zeit?“ iš "Herbsttag“), Mirtis (,Der Tod ist gross" iš „Buch der Bilder“ ${ }^{\prime 1}{ }^{11}$, Sapnas, Budejjimas, "Vigilia“, Giesmè, Nuojauta, Likimas, Širdis. Visi šie simboliai, l̨esminti garsais ir kartojamais vardais, leidžia poetikai persismelkti $\mathfrak{i}$ vaizdinio erdvę, pakilti i transcenduojanti veiksmą. Taip scenoje atsiranda bendri egzistencialistiniai motyvai: vandenyno krantas, laivai, „narveliai - langai“, burès, jūreiviai (iš 
Kokoshkos „Sapnuojančiu berniuku“"), „Rudenio daina“ (iš O. Miloszo poezijos), meilès eilèraštis „Apkabink mane“ (iš Jaques Prevert „Histories“) ir daug kitų kontekstu, vedančiu prie Rilke's savotiškame Narbutaitès ideju secesijos labirinte konstruojant asmenini santyki su operos objektu Rilke's tema. Vis delto esminis egzistencializmo motyvu pynimo principas operoje tampa būtent ",sapnas" - dienos sapnu, Jungo pasąmonės išlaisvinimo ir Jasperso "transcendentinių šifrų", pasąmonès ir prisiminimu vaizdinys. Jam akompanuoja tolimos istorijos fono bei realaus žmogaus, įmesto i priešišką pasauli, tragiško likimo idèja. Ją realizuoja „dienos-sapnu“ dramaturgija ir tolimi-artimi kontekstai, kartu dar labiau pakyleddami „Kornetą" ¡ idejju - transcendentiniu šifru - sfera, o jo pirmajji autorių Rike'ę išvesdami iš konkretaus epochų susidūrimo ir literatūros reminiscenciju vingio i jo trokštama kelione epochu laiku. Ypatingą viziju gelmę čia atveria aliuzija i̇ Jungo Bokštą kaip vidinio išsilaisvinimo dramaturgija, archetipu raišką ir transformaciją per kon- tekstų skleidimąsi. Taip transformuojami Rilke's egzistenciniai motyvai jungiškai išlaisvina ir pačią operos-sapno idèja, kaip to siekia "improvizacijomis“ jos autorè.

„Korneto" libretas (jo autorè Narbutaitè) savo painia struktūra iškelia keletą itin reikšmingų egzistencialistinių Rilke's akcentų. Tai tarsi literatūrinis „Rilke's algoritmas“, kur svarbiausia gyvenimo ir mirties vienuma („Leben und Tod: sie sind im Kerne Eins") ir individo, vedamo gyvenimo aistros, metimasis i liepsną („Und wirft sich selber in die reine Flam$\left.\mathrm{me}^{\prime \prime}\right)^{12}$. Tai palydima kontekstu, ypač Georgo Traklio poezijos. Ši idejja iprasminama vèliau atsirandant meilès linijai kulminaciniame paveiksle Bokštas. Čia išnyksta "kitos erdvès“, lieka tik sapno, visiškai iki galo „atsiduodama sapnui“. Sapnas susilieja su egzistencijos himnu.

\section{Kornetas ir Grafiené:}

$\mathrm{Ak}$, atsiduokim sapnui, tegu jis mus liūliuoja

Čia nèra jokio vakar, jokio rytoj, Mes tekam pro viską tarsi virpėjimas oro. Jokio vakar, jokio rytoj O, saldžioji daina. ${ }^{13}$

\section{MUZIKA: EGZISTENCIALIZMO VIRSMAS GARSU PASAULIU}

Egzistenciniai motyvai operoje suveriami ant vienos idejjinès ašies - muzikos meno absoliuto. Ši estetine samprata išskleista egzistencializmo filosofų veikaluose (Anri Bergsono, Martino Heideggerio), pavertusių muziką pamatine savo teorijų vertybe. Čia ypač svarbus neišbaigtumo-užuominos principas, esmingas Narbutaitès muzikos struktūrų kūrybai (taip pavadinta oratorija "Skiautinys mano miestui“, 1998). Tai ir jos originali raiška, ir kūrybos maniera, bylojanti, kad „,̌mogiškoji būtis negali būti išsakyta iki galo“14. Meditacijos, neišbaigtumo, tylèjimo, šešèlinè gelmès dimensija persmelkia viršlaikę operos paribių erdvę Korneto istorija. Kaip rašo Heideggeris, „svarbiausia žodžio minties prasmè perteikiama tylëjimu, užuomina, pauze... Todèl užmarštis, ì kurią kūrinys gali nugrimzti, nèra niekas - ji dar yra sauga ${ }^{\star 15}$. Būtent toks yra ir Narbutaitės mu- 
zikinis kalbejjimas, užuomina, pauzè, sauga. Būties prasmė sustingusi, medituojama „bekalbès muzikos, dailès ir architektūros kūrinių. Filosofas - poetas perima seną meno kaip gyvenimo raiškos idejja sujungdamas filosofija, meną ir gyvenimą i vientisą ontologini fenomeną"16, kuri savo muzikoje detaliai savitai realizuoja kompozitorè.

Būtent čia, „Kornete“, meno kūrinys virsta specifine istorinių būties struktūrų, t. y. pasaulio kultūros, bendruoju meno kūriniu (Gesamtkunstwerk), kodavimo ir raiškos forma, savita daugiasluoksne Secesija. Toki egzistencialistų tarsi jai diktuojamą daugiasluoksni meno gyvenimą istruktūrina ir ìvardina Narbutaitè, apčiuopdama ivvairių menų ir istorijos sąsajas, apdairiai pavadindama opera „improvizacija pagal Rilkę ${ }^{\text {"17. }}$. Mat čia pasineriama $\mathfrak{i}$ ", atotrūkị" tarp transformuojamų meno formų ir sudètingo žmogiškojo metarefleksijų konteksto, tarsi statoma meno kūrinio šventovè.
Tokioje šventovės transcendentinejje erdvejje ir gyvena „Kornetas“, prisimenant muzikologo Šarūno Nako komentarą

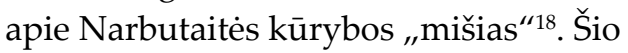
meno pasaulio - kontekstų harmonijos ir konfliktų sąveikų secesijos skliautas, transcendencijos kelias, aukštesnioji erdvè issikūnija per muziką. Kūrinyje dalyvauja ir vaizdo, ir žodžio poetikos virpesiai, judejimai, kurdami savaji labirinta, psichologinius bokšto, sapno, vandenyno vaizdinius, ženklus ir kodus. Bet būtent muzika tampa ta sakralumo dimensija, aukštesniaja jèga transcendentinių šifrų sklaidai, savo erdvëje panardinančia visus Secesijos posūkius ir lemiamus taškus. Taip išeinama ir už Rilke's, ir už Kokoshkos, ir už Jungo gelmès psichologijos diskursų i egzistencialistinę , žmogaus svetimame pasaulyje" projekciją ir būties beribiškumo žymèjimo ateinančiame meno kūrinyje ideją. Kūrinys Narbutaitei tampa šito beribiškumo ženklu.

\section{EGZISTENCIALIZMO GRAFIKA MUZIKOS METAFIZIKOJE}

Egzistencializmo motyvai, stiprejjantys asmeniniame laiko pojūtyje, igyja dar tikslesnes reikšmes naujausioje Narbutaitès kūryboje. Pereinama ì savotišką egzistencinès filosofijos sąvokų grafiką muzikos kalboje. Tai ir minèti infinito, sustabdyto laiko, sutrupintos faktūros skiautiniai, atveriantys vis daugiau erdvès laukimui, isiklausymui i tylą, trukmès suvokimo brendimui, estetiniam sklaidos aido išgyvenimui. Toks yra naujausias Narbutaitès darbas, parašytas Thomo Manno festivalio užsakymu, pjesè fortepijonui „Tuštumoje“, nuskam- bejusi Th. Manno name Nidoje $2016 \mathrm{~m}$. rugpjūčio mènesi. Th. Manno festivalis penkerių metų ciklu gilinosi ì Pirmojo pasaulinio karo refleksijas. Narbutaitè savo ruožtu pasinèrè $\mathfrak{i}$ jas gilindamasi $\mathfrak{i}$ Georgo Traklio poezija, su kuria jau iš esmès susiduriame kontekstualiame Rilke's „Korneto“ interpretavime. Kompozitorè sugestyviai atveria tiek literatūrinę, tiek vizualinę, tiek filosofinę egzistencijos ir kūrybos sankirtą. Jos dimensija išnyra kaip „Tuštuma“, filosofinè kategorija, kurią autore ivvaizdina garsais. Prisilietimo gestas čia yra lemiantis. Taip 
ji prisiliečia ir prie savo kūrinio - virtualiai vizualia kultūrologine ižvalga prie subtilaus muzikos rašto. Žodis kaip ženklas tarsi pats savaime išnyra iš galingų amžių sandūros poetikos gelmių. Ji rašo: „1914 m. praejus kelioms dienoms po vieno žymiausiu savo eilèraščiu - Grodek - sukūrimo, Krokuvos karineje ligoninèje nusižudo 27-erių metu kariuomenės savanoris Georg Trakl. Tais pačiais 1914 m. 35-erių metų Paul Klee kelionejje i Tunisą patiria inspiracijas, nuo kuriu prasideda tikros jo tapybos proveržis. Pavadinimas „Tuštumoje“ išsikristalizavo jau parašius kūrini. Ji galima sieti su struktūrine muzikos išraiška, redukuota garsų kalba, tuščiu intervalų dominavimas, skaidri faktūra, tarsi betikslè muzikos tékmé neapibrèžtoje teritorijoje tarp statikos ir dinamikos, kurioje garsu judejimas gali kurti statikos iliuziją, o statiški momentai slèpti savyje judesio nuojautą. Toks pavadinimas prašosi paliekamas be komentarų. Tačiau suprantu, kad itin platus seman- tinis žodžio „Tuštuma“ laukas, apimantis skalę nuo nušvitimo iki desperacijos, neišvengiamai įtakos šio opuso suvokimą, kiekvienu atveju labai individualų. Muzikinès kompozicijos dažniausiai slepia savyje daugiabriaunių ir net prieštaringu prasminių interpretacijų galimybę. Filosofinė Dao ar Heideggerio tuštuma (die Leere), egzistencinè dvasios tuštuma ar tiesiog tuščia erdvė, kurioje gali bet kas atsirasti. Garsai gali atverti tuštumą ir tuo pat metu ją užpildyti. “19

Narbutaitès komentaruose labai apdairiai atsiremiama i̇ šią sampratą „Tuštuma“, paliekant jai visas kitas įmanomas interpretacijos žaidimo galimybes. Tuo tarpu pats kūrinys toliau tęsia egzistencializmo metaforos muzikini grafinį i̇vaizdinimą - laiko linijos trukmes, igarsinimą išplèsdamas laukimo ir tylos skalę, vis daugiau erdvès palikdamas filosofijai, meditacijai ir kultūriniu jungčiu kontekstams. Iškylant asociacijai su pranašišku varpu gausmu, dūžių ir subyrèjimo simbolika.

\section{IŠVADOS}

Egzistencializmo motyvai Narbutaitès „Kornete“ ateina per jos ilgameti pasinėrimą i Rilke's kūryba, istorinių aplinkybiu nulemtą artumą ir daugiapoli multikultūrinių kontekstų pasaulį.

Muzikos diskursyvus kontekstualumas, būdingas Narbutaitei, šiuo atveju siejamas su XX a. pr. idejų ir naujoviu, kaip gelmès psichologijos, atsiradimu ir kitais moderno kultūros proveržiais.

İkūnijamos pamatinės egzistencializmo nuostatos:

1) žmogaus kūrybinès laisvės pirmumas prieš visuomeninès būties sistemą;
2) žmogaus individo pasimetimas, buvimas svetimu ji supančiame pasaulyje;

3) iš to kylanti jo vienatvè ir pasaulio virsmų beprasmybè, kliudanti asmeniniam proveržiui;

4) kitokios erdvės ilgesys;

5) prisilietimas prie amžinybès gelmès.

Tai yra esminiai Narbutaitès kūrybos motyvai, išskiriantys ją kaip transcendentinès erdvès ir praeities nostalgijos kompozitorę - istorijos tiesu daugialypumo atkūrejją lietuviškoje muzikoje. 
Opera „Kornetas“ projektuoja tris esmingas egzistencializmo muzikines transformacijas:

1) transcendentiniu šifru (Jaspersas) išskleidimą audiovizualinèje sferoje: scenografijos, literatūros ir muzikos sąveika;

2) gelmès psichologiją (Jungas) ir jos inspiruotų "dienos sapnu" perkèlimą i operos audiovizualinę viziju kalbą;

3) muzikinių dramų (Wagneris) melodinio rečitatyvo begalybės virsmą - muzikinès pasaulio valios idejjos išsiskleidimą ,per Rilkę“ akustinejje sutrupèjusio laiko (literatūros klasikos žodžio "ląstelių") erdvëje. Kalbame apie melodijos ištirpdymą gelmèje, archetipinèse pasaulio dimensijose, kur tvyro

\section{Literatūra ir nuorodos}

1 Audronè Žiūraitytè, Skiautinys mano miestui. Monografija apie Onutès Narbutaitès kūryba. Vilnius: Lietuvos kompozitorių sajunga, Lietuvos muzikos ir teatro akademija, 2006, p. 54.

2 Antanas Andrijauskas, Grožis ir menas. Vilnius: Dailès akademijos leidykla, 1995, p. 562. Karl Jaspers, Filosofijos ivadas. Vilnius: Pradai, p. 50.

3 Šarūnas Nakas, Ǐžangos žodis O. Narbutaitès jubiliejiniam kūrybos vakarui "Vieno dešimtmečio hoketas". Vilnius, Nacionalinè dailès galerija, 20160908.

4 Karl Jaspers, Filosofijos ivadas. Vilnius: Pradai, 1989 , p. 51.

5 Ten pat, p. 52.

6 Reiner Maria Rilke, Poezija. Vertè L. Petravičius. Vilnius: Vaga, 1975, p. 21.

7 Onutè Narbbutaite, Kornetas. Libretas. Mašinraštis. Vilnius, 2014, p. 7.

8 Ten pat, p. 25.

9 Carl Gustav Jung, Prisiminimai, vizijos, apmąstymai. Vilnius: Margi raštai, 2010, p. 318.; Carl grèsmès artumo nuojauta, panardinta „tolimo karo" pašvaisčių peizaže.

Šios egzistencializmo motyvų transformacijos Narbutaitès kūryboje, ypač operoje „Kornetas", panyrant ì Rilke's kūrybos gelmių ir paribių kontekstus, yra išskirtinis kultūros sferų sąveikos reiškinys (minètina jo kūrèjų grupè: režisierius Gintaras Varnas, kostiumų dailininkas Juozas Statkevičius, scenografẻ Medilè Šiauditytè, libreto ir muzikos autorè Onutė Narbutaitè) dabarties lietuvių muzikoje, inspiruojantis tolesnes šio meno - gyvenimo projekto refleksijas. Tai galima ivvardinti kaip Rilke's fenomena lietuviu muzikoje, siekiančioje atkurti save pasaulyje ir pasauli savyje.
Gustav Jung, Beiträge zur Symbolis des Selbst. Olten und Freiburg im Breisgau, Walter Verlag, 1976, S. 329.

10 Jūratè Landsbergytè-Becher. Archetipo Savastis raiška naujojoje lietuviu vargonu muzikoje. Meno daktaro tiriamasis darbas. Vilnius: Lietuvos muzikos ir teatro akademija, 2014, p. 39.

11 Reiner Maria Rilke, Gedichte. Poezija. Vertè Sigitas Geda. Vilnius: Lietuvos rašytojų sąungos leidykla, 1996, p. 57-103.

12 Narbutaitè, Kornetas, p. 27.

13 Ten pat, p. 40-42.

14 Andrijauskas, Grožis ir menas, p. 568.

15 Martynas Heidegeris, Meno kūrinio prigimtis. Grožio kontūrai. Vilnius: Mintis, 1980, p. 244.

16 Andrijauskas, 1995, p. 566-567.

17 Narbutaitè, Kornetas, p. 1.

18 Šarūnas Nakas, Ižangos žodis O. Narbutaitès kūrybos vakarui.

19 Onutè Narbutaitė, Tuštumoje. Autorès anotacija. Mašinraštis, Vilnius, 2016. 